\title{
Development of Flake Powder Metallurgy in Fabricating Metal Matrix Composites: A Review
}

\author{
Genlian Fan $\cdot$ Run Xu $\cdot$ Zhanqiu Tan $\cdot$ Di Zhang $\cdot$ Zhiqiang Li
}

Received: 9 June 2014/Revised: 26 August 2014/Published online: 26 September 2014

(C) The Chinese Society for Metals and Springer-Verlag Berlin Heidelberg 2014

\begin{abstract}
Powder metallurgy (PM) is one of the most applied processes in the fabrication of metal matrix composites (MMCs). Recently, a novel PM strategy called flake PM was developed to fabricate MMCs with nano-laminated or hierarchical architectures. The name "flake PM" was derived from the use of flake metal powders, which could benefit the uniform dispersion of reinforcements in the metal matrices and thus result in balanced strength and ductility. Flake PM has been proved to be successful in the dispersion of nano aluminum oxides, carbon nanotubes, graphene nano-sheets, and microsized $\mathrm{B}_{4} \mathrm{C}$ particles in aluminum or copper matrix. This paper reviews the technique and mechanism developments of flake PM in previous studies, and foresees the future develop of this new fabricating method.
\end{abstract}

KEY WORDS: Metal matrix composites; Flake powder metallurgy; Micro- and nano-composites; Architectures; Strength and ductility

\section{Introduction}

With excellent mechanical and functional properties, metal matrix composites (MMCs) have been extensively studied and widely applied in the past decades. However, there are still some disadvantages that hinder the further application of MMCs. Firstly, the preparation routes of MMCs are usually costly and hard to control. Secondly, the ductility and toughness are usually quite low for the MMCs with high volume fraction of reinforcements. The solutions of those two problems are keys for the future development of MMCs [1, 2].

Generally, the fabricating routes of MMCs could be divided into liquid state and solid state methods. The solid

Available online at http://link.springer.com/journal/40195.

G. Fan $\cdot$ R. Xu $\cdot$ Z. Tan $\cdot$ D. Zhang $\cdot$ Z. Li $(\bowtie)$

State Key Laboratory of Metal Matrix Composites, Shanghai

Jiao Tong University, Shanghai 200240, China

e-mail: lizhq@sjtu.edu.cn state methods, which were mainly powder metallurgy (PM) methods, are now experiencing a rapid developing period in application. With PM methods, the control of interface below the melting point of the matrix, the dispersion of nano or sub-micron reinforcements, and the precision forming of MMCs became possible, which promises a wide prospect for MMCs [1-3].

The PM producing methods for MMCs usually consisted of two steps: reinforcement-matrix mixing and powder consolidation. The basic requirement for the mixing step was uniform dispersion of the reinforcements, which has increasing difficulty when the reinforcements become finer. There are many methods developed to reach this goal: mechanical mixing, high-energy ball milling, solutionassisted dispersion, and so on. However, the dispersion of reinforcements still remains to be difficult in the PM methods, especially when the reinforcements are nano sized. The powder consolidation step requires a process consisting of powder compacting (e.g., cold pressing, hot pressing, isostatic pressing, etc.), sintering (e.g., heating, spark plasma sintering, etc.), and deformation processing (e.g., extrusion, rolling, forging, etc.). This step would 


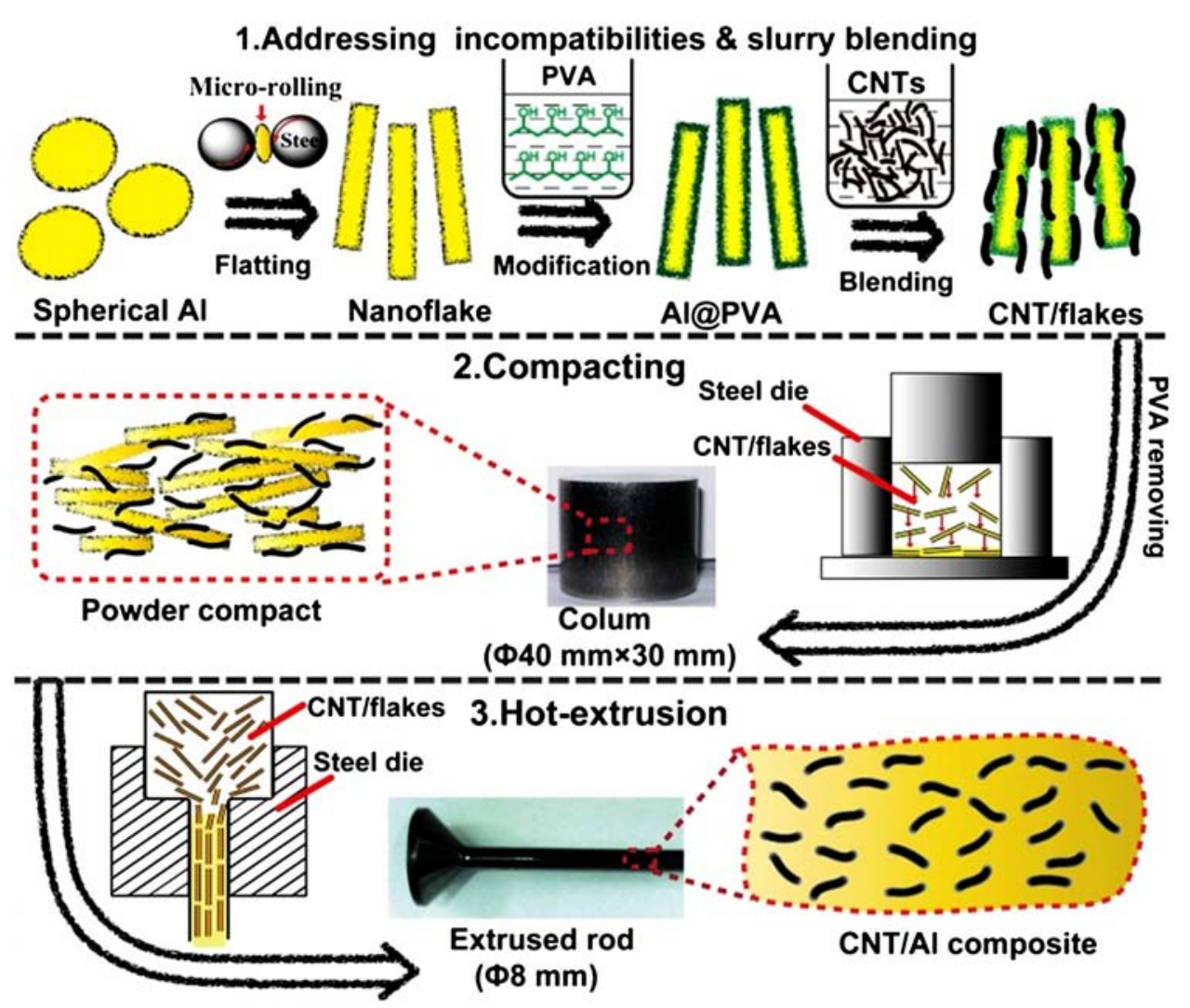

Flake PM

Fig. 1 Schematic diagrams of the flake PM producing route of CNTs/Al composites [4]

determine the relative density and structure of the bulk material, and influence the material properties directly [3].

Since 2010, the research group of PM MMCs from Shanghai Jiao Tong University has explored a novel PM strategy called flake PM, which used flake powders to get better reinforcement dispersion, and this resulted in the special microstructures in the bulk materials. In the recent serial reports, it has been proved that, it is possible to fabricate strong and ductile MMCs with appropriate design of flake PM routes. In the following, the preparing route, the microstructure characteristic, the properties, and mechanism developments of the MMCs produced by flake $\mathrm{PM}$ will be reviewed.

\section{The MMCs Produced with Flake PM}

The idea of flake PM was based on using flake-shaped metal powders as composing units. In a typical flake PM process, three steps are involved:

(1) Preparation of flake metal powders. The flake powders can be easily obtained by ball milling the spherical metal powders;
(2) The mixing of flake powders and the reinforcements;

(3) The shaping and consolidation of the composite powder.

Flake PM has succeeded in MMCs fabricating in $\mathrm{Al}_{2} \mathrm{O}_{3} /$ $\mathrm{Al}$, carbon nanotubes (CNTs)/Al, $\mathrm{CNTs} / \mathrm{Cu}$, graphene/Al, and $\mathrm{B}_{4} \mathrm{C} / \mathrm{Al}$ system, which resulted in improvement of the Young's modulus, tensile strength, and toughness of the materials. Figure 1 shows the schematic diagrams of a typical flake PM route for preparing CNTs/Al composites [4].

\subsection{Reinforcement-Matrix Composing in MMCs Produced with Flake PM}

The first use of flake powders to disperse reinforcements in metal matrix was reported by $\mathrm{Li}$ et al. [5]. Along with the subsequent studies [4, 6], flake PM was proved to be useful in the dispersion of CNTs in $\mathrm{Al}$ (Fig. 2a). Al flake powders (about $0.4 \mu \mathrm{m}$ in thickness, $70 \mu \mathrm{m}$ in diameter, and 175 in aspect ratio) with PVA coatings introduced by stirring in $5 \%$ PVA aqueous solution were used to absorb CNTs. The CNTs were surface functionalized with carboxyl groups $(-\mathrm{COOH})$ and dispersed in deionized water with sonic and anionic surfactant of sodium dodecyl benzene suffocated. 

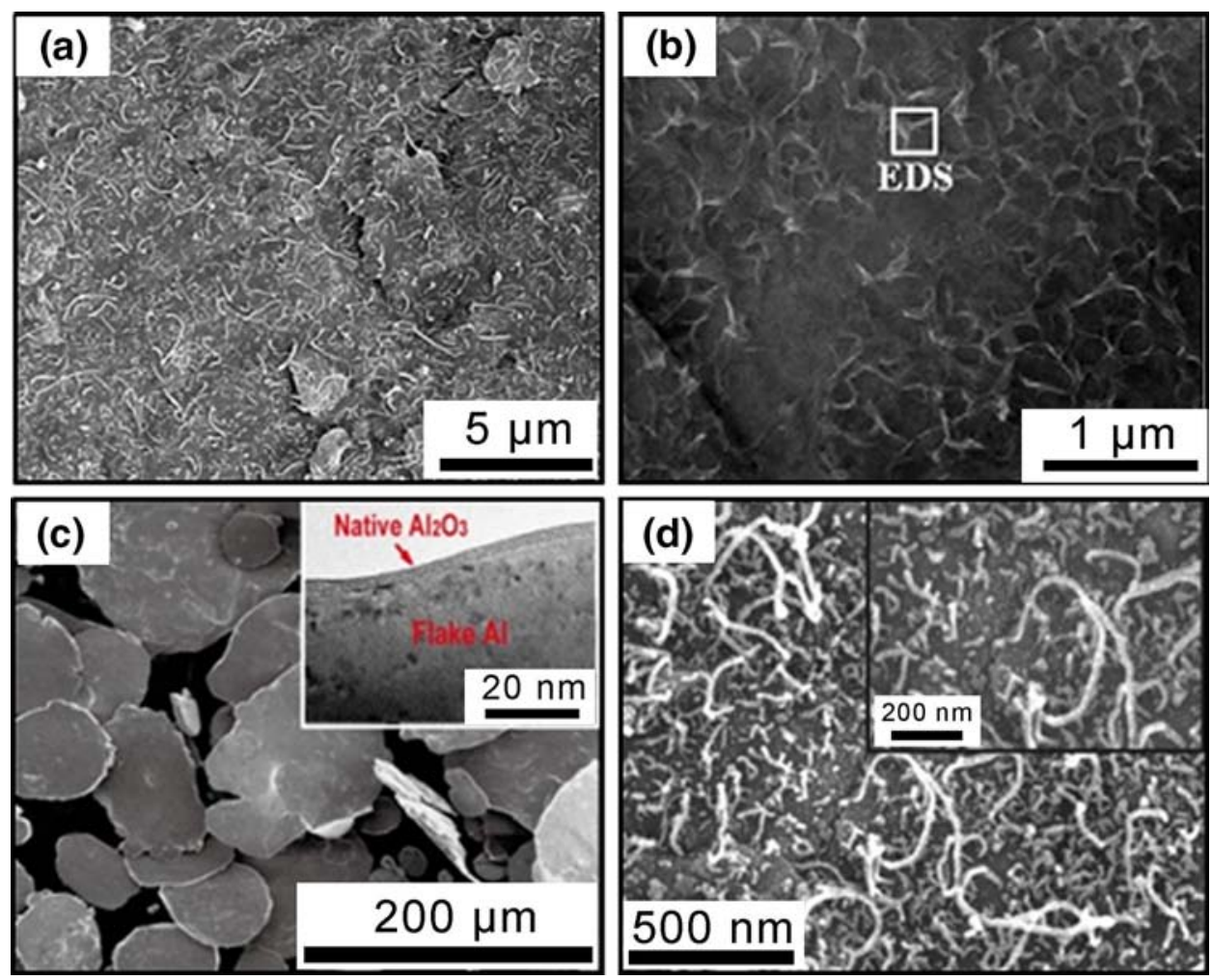

Fig. 2 SEM images showing the distributions of absorbed CNTs a, GO b, native $\mathrm{Al}_{2} \mathrm{O}_{3}$ flakes $\mathbf{c}$, the in situ synthesized CNTs on surfaces of $\mathrm{Al}$ flake powders $\mathbf{d}$

The planes in Al flake powders suited the CNTs well geometrically, the high specific surface area (about $8 \mathrm{~m}^{2} / \mathrm{g}$ ) of $\mathrm{Al}$ flake powders allowed high CNTs capacity in $\mathrm{Al}$ powders, and the hydroxyl group of the PVA coatings and carboxyl group on CNTs surfaces could be bonded with hydrogen bonds, which ensured the strong connection of CNTs and Al flake powders. When the thickness decreased to $0.2 \mu \mathrm{m}$, Al flake powders could uniformly absorb as much as 20 vol.\% CNTs, which was 100 times of the $10-\mu \mathrm{m}$-diameter spherical Al powders can do. Similar route succeeded in dispersion of CNTs in $\mathrm{Cu}$, too [7].

Also, Wang et al. reported the dispersion of graphene nanosheets (GNSs) in Al flake powders uniformly with a similar process [8], which was the first reported successful production of GNSs reinforced bulk MMCs. Due to the two dimensional shape of graphene, it is very difficult to disperse GNSs flat and uniformly in metal matrix with other methods. As seen in Fig. 2b, the flake-shaped graphene oxide (GO) nanosheets, which were functionalized with carboxyl groups, could be absorbed uniformly on the surface of PVA-coated Al flake powders. The GO nanosheets could be reduced to GNSs at $550{ }^{\circ} \mathrm{C}$, resulting in the uniform dispersion of GNSs in $\mathrm{Al}$ flake powders.

The Al flake powders were also used in the in situ composing of $\mathrm{Al}$ matrix composites. After heating in air for hours, native $\mathrm{Al}_{2} \mathrm{O}_{3}$ membranes could be formed on the surfaces of $\mathrm{Al}$ flake powders (Fig. 2c). Those $\mathrm{Al}_{2} \mathrm{O}_{3}-\mathrm{Al}$ flake powders were used to produce laminated $\mathrm{Al}_{2} \mathrm{O}_{3}-\mathrm{Al}$ composites [9]. Another in situ route called polymer pyrolysis chemical vapor deposition (polymer pyrolysis CVD) was also studied to uniformly synthesize CNTs on the surfaces of Al flake powders (Fig. 2d) [10, 11]. Uniform polyethylene glycol-citric acid-Co( $\left(\mathrm{NO}_{3}\right)_{2}$ precursor coatings on Al flake powders were firstly obtained by stirring in alcohol solution. Then, the Al flake powders were dried and heated to make the precursor coating react and pyrolyze, producing uniformly dispersed catalyst particles and carbon source gases, then synthesizing CNTs in situ in $\mathrm{Al}$ powders. The $\mathrm{Al}$ flake powders, which were used as the substrates in polymer pyrolysis CVD routes, were important in the uniform absorption of the precursor coating, which would affect the uniform dispersion of $\mathrm{Co}$ catalyst particles and the uniform synthesis of CNTs.

In addition to nano-sized reinforcements, flake PM was also used in micro-sized particle reinforcements [12, 13]. The flake powders would likely support each other in the packing state, which would result in much lower apparent density. Thus, the reinforcements would be divided by the flake powders uniformly in the mixed powder, and result in uniform dispersion of high volume fraction of reinforcements in the MMCs, as shown in Fig. 3. In $\mathrm{B}_{4} \mathrm{C}$ particle $(7 \mu \mathrm{m}) / \mathrm{Al}$ bulk composites with $32 \mathrm{vol} . \% \mathrm{~B}_{4} \mathrm{C}$ shown in 
(a)

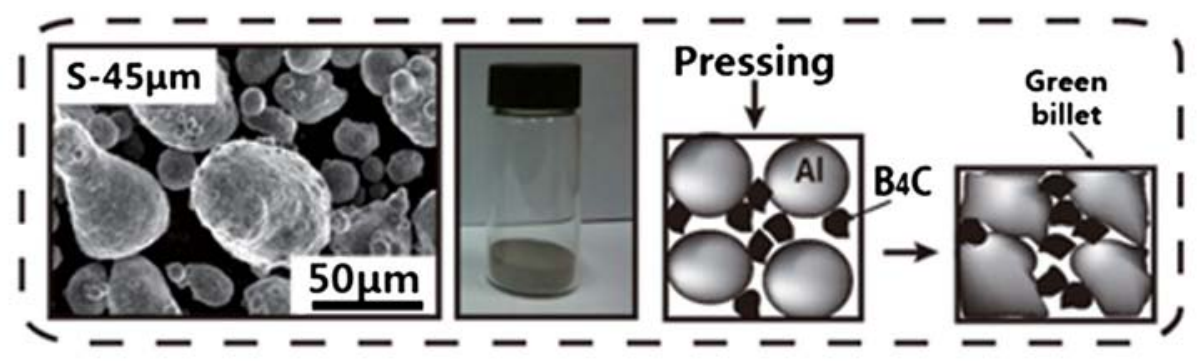

(b)

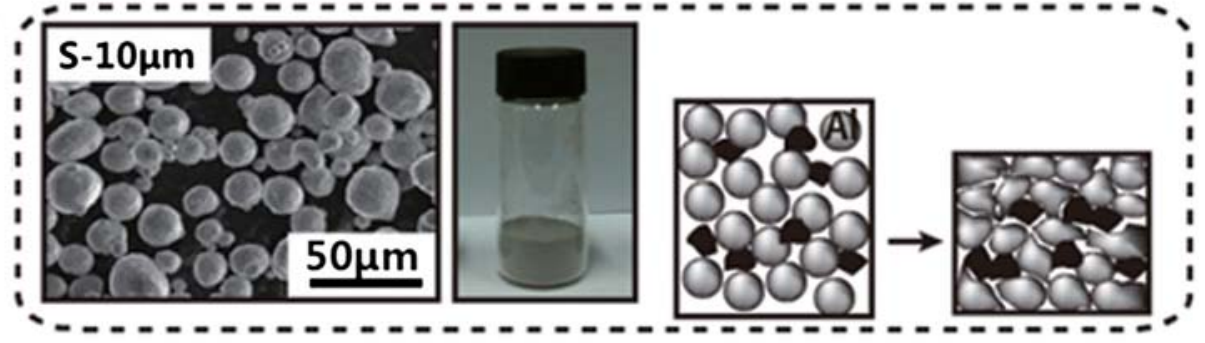

(c)

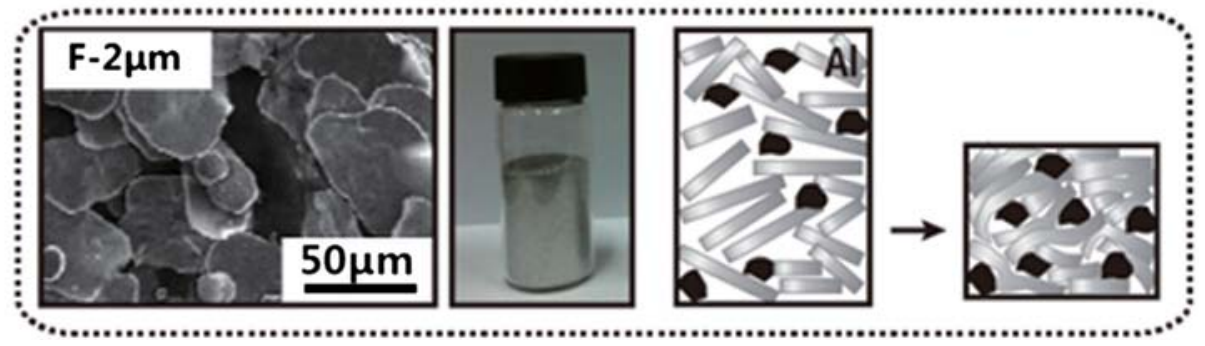

Fig. 3 The morphologies of different $\mathrm{Al}$ powders, $\mathrm{Al}$ powders $(5 \mathrm{~g})$ in transparent bottles and illustrations of the $\mathrm{B}_{4} \mathrm{C} / \mathrm{Al}$ composite powder compacting for composites: a PM (spherical, $45 \mu \mathrm{m})$, b PM (spherical, $10 \mu \mathrm{m})$, c flake PM $(2 \mu \mathrm{m}$ in thickness)

Fig. 4a-f, compared with the composites produced by conventional $\mathrm{PM}$ which used spherical $\mathrm{Al}$ powders with diameters of 45 and $10 \mu \mathrm{m}$, obvious improvements of uniformity can be seen in the composites produced by flake PM which used flake powders of $2 \mu \mathrm{m}$ in thickness. The average adjacent interspace of $\mathrm{B}_{4} \mathrm{C}$ in flake $\mathrm{PM}$ produced composites fitted the theory value of uniformly dispersed models [14], while obvious deviations existed in conventional $\mathrm{PM}$ produced $\mathrm{B}_{4} \mathrm{C} / \mathrm{Al}$ composites, which indicated the non-uniform distribution of $\mathrm{B}_{4} \mathrm{C}$ in the materials.

\subsection{Material Consolidation, Microstructure, and Properties of MMCs Produced with Flake PM}

Like the conventional PM, the consolidation processes of flake PM generally consist of powder compacting, sintering, and deformation processing. The specificity of flake $\mathrm{PM}$ is, when the flake shape of metal powders were maintained in the composites, it would influence the microstructure of the bulk materials, leading to the formation of nacre-like nanolaminated structures.

It is well-known that in nacre, the laminated assembly of alternating protein collagen layers $(10-50 \mathrm{~nm}$ thick) and aragonite tablets (200-900 nm thick) contributes to remarkable mechanical properties far beyond what can be achieved by man-made composites [15]. In flake PM routes, such a nanolaminated assembly could also be inherited from the flake powders. In powder compacting process, in order to minimize the potential energy under the applied force fields, the flake powders would tend to lie flat on each other irregularly. In extrusion process, the extrusion direction is parallel to the axis of the compacted column, so the layer direction of the final product is changed to be parallel to the axis of the extruded rods.

Figure 5 shows the nanolaminated structure in $\mathrm{Al}_{2} \mathrm{O}_{3}-\mathrm{Al}$ [9] and CNT-Al [16] composites. It can be seen that the extruded multilayer structures with alternating $\mathrm{Al}$ (pure $\mathrm{Al}$ : $300-500 \mathrm{~nm})$ and reinforcement $\left(\mathrm{Al}_{2} \mathrm{O}_{3}: \sim 10 \mathrm{~nm}\right.$; CNTs: $\sim 50 \mathrm{~nm}$ ) layers can be readily observed from the vertical section of the extruded samples.

When the flake shape of metal powder was destroyed after the mixing process, instead of laminated structures, uniform dispersion of reinforcement particles and ultra-fine grain (UFG) matrix would be formed. Additionally, for in situ composed $\mathrm{Al}_{2} \mathrm{O}_{3} / \mathrm{Al}$ flake powders mentioned in Sect. 2.1, $\mathrm{Al}_{2} \mathrm{O}_{3}$ nano dispersoids could be introduced in the composites. The nano-sized $\mathrm{Al}_{2} \mathrm{O}_{3}$ formed on $\mathrm{Al}$ flake powders could be fractured during extrusion with high 

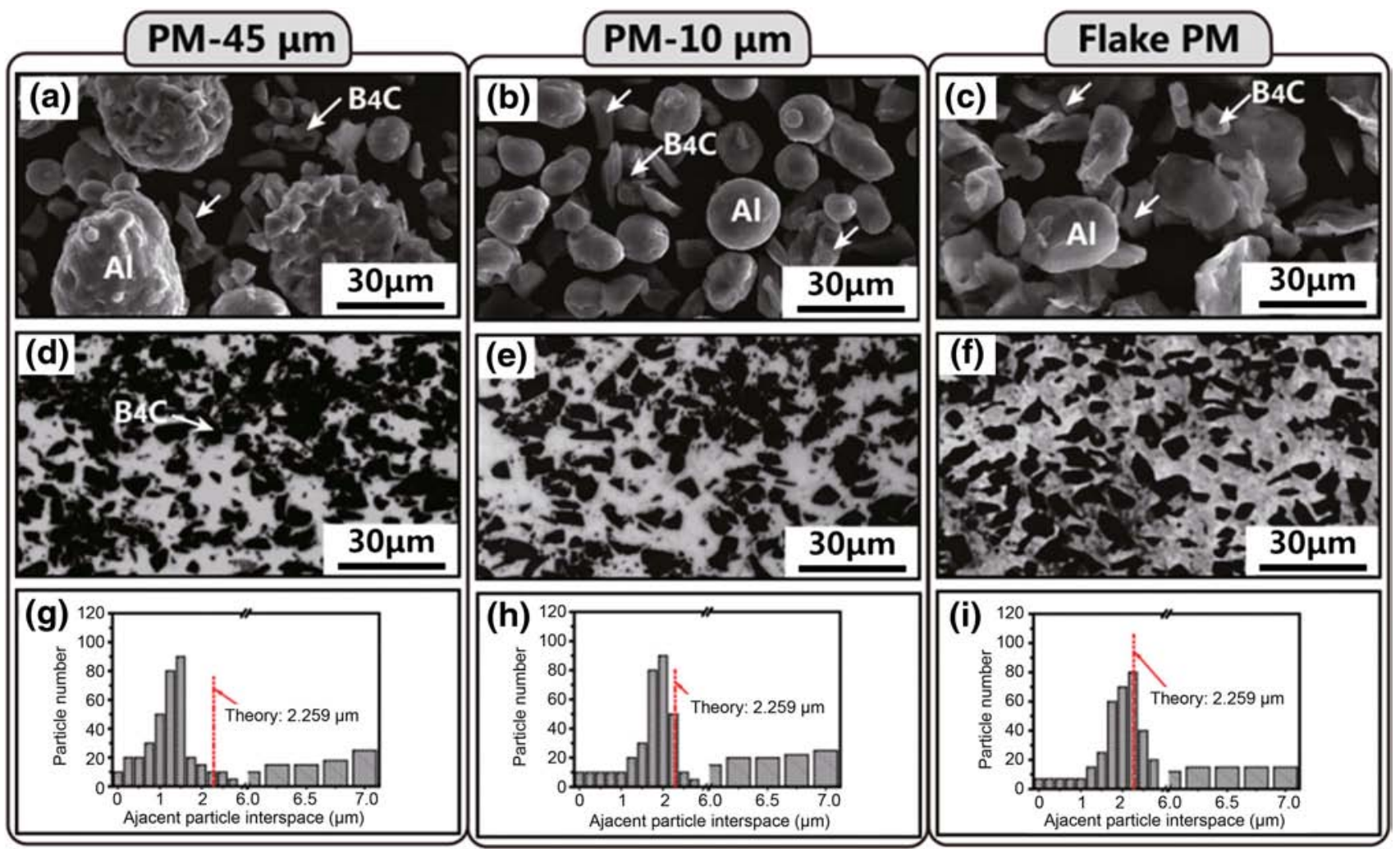

Fig. 4 The reinforcement distribution in the 32 vol.\% $\mathrm{B}_{4} \mathrm{C} / \mathrm{Al}$ composite powders and the extruded composites made by PM (spherical $45 \mu \mathrm{m}$ ), PM (spherical $10 \mu \mathrm{m})$ and flake PM $(2 \mu \mathrm{m}$ in thickness): a-c SEM images of the composite powders, $\mathbf{d}-\mathbf{f}$ OM images of the extruded composites, $\mathbf{g}-\mathbf{i}$ the interspace statistics of adjacent $\mathrm{B}_{4} \mathrm{C}$ particles in the extruded composites via OM image analyzer, and the theoretical interspace of $2.259 \mu \mathrm{m}$ for $32 \mathrm{vol} . \% \mathrm{~B}_{4} \mathrm{C}(7 \mu \mathrm{m}) / \mathrm{Al}$ composites is also marked by red dashed line
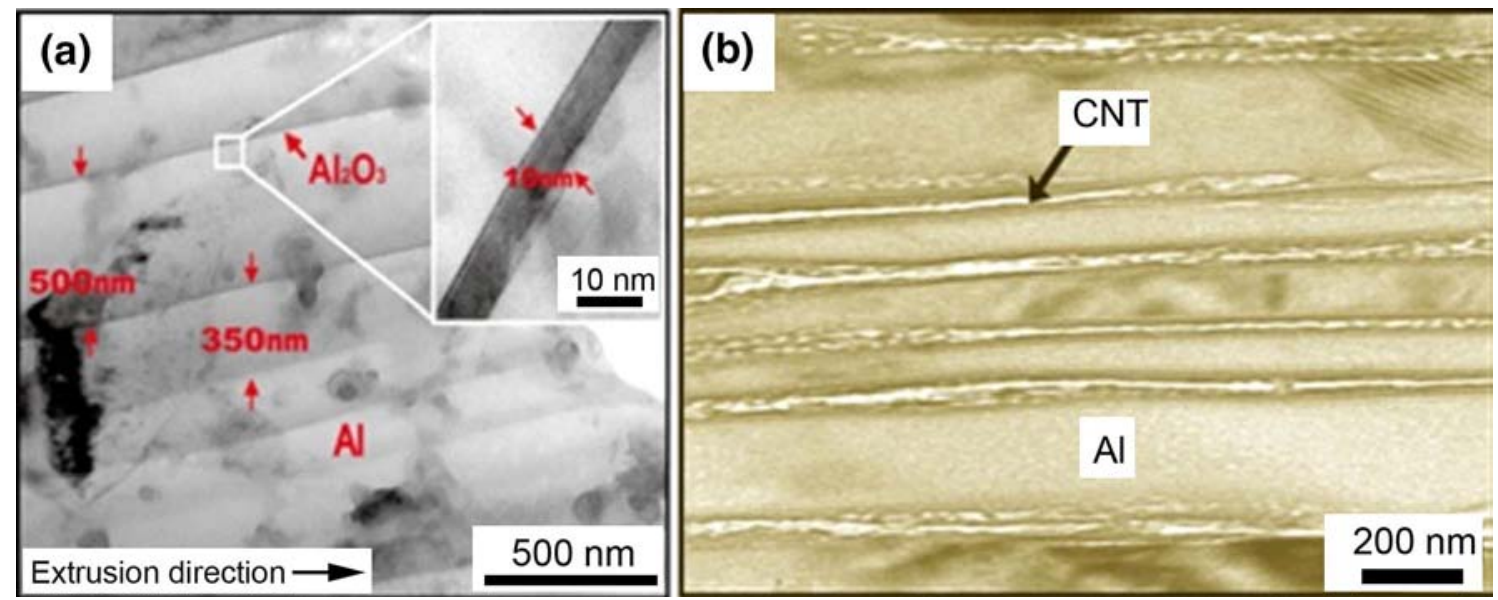

Fig. 5 Laminated structure of flake PM produced $\mathrm{Al}_{2} \mathrm{O}_{3} / \mathrm{Al}$ composites a, CNTs/Al composites b

extrusion ratio or high extrusion rate, and then entered $\mathrm{Al}$ grains during the grain boundary migration, resulted in the $\mathrm{Al}_{2} \mathrm{O}_{3}$ nano dispersoids in flake $\mathrm{PM}$ producing $\mathrm{B}_{4} \mathrm{C}$ / $\mathrm{Al}\left(\mathrm{Al}_{2} \mathrm{O}_{3}\right)$ composites $[13,17,18]$. Figure 6 shows the microstructures of the 16 vol. $\% \mathrm{~B}_{4} \mathrm{C} / \mathrm{Al}$ composites fabricated by flake PM. As it can be seen, the $\mathrm{B}_{4} \mathrm{C}$ particles were distributed uniformly in the matrixes (Fig. 6a, c). When the
Al flake powders were not surface oxidized, the Al matrix grains would coarsen after the high temperature sintering (Fig. 6b). When the $\mathrm{Al}$ flake powders were surface oxidized, many $\mathrm{Al}_{2} \mathrm{O}_{3}$ nanoplatelets would be well dispersed inside the matrix grains in $\mathrm{B}_{4} \mathrm{C} / \mathrm{Al}\left(\mathrm{Al}_{2} \mathrm{O}_{3}\right)$, and the $\mathrm{Al}$ grains would remain ultra-fine under the inhibition of nano $\mathrm{Al}_{2} \mathrm{O}_{3}$ (Fig. 6d). Therefore, with artful design and process control, 

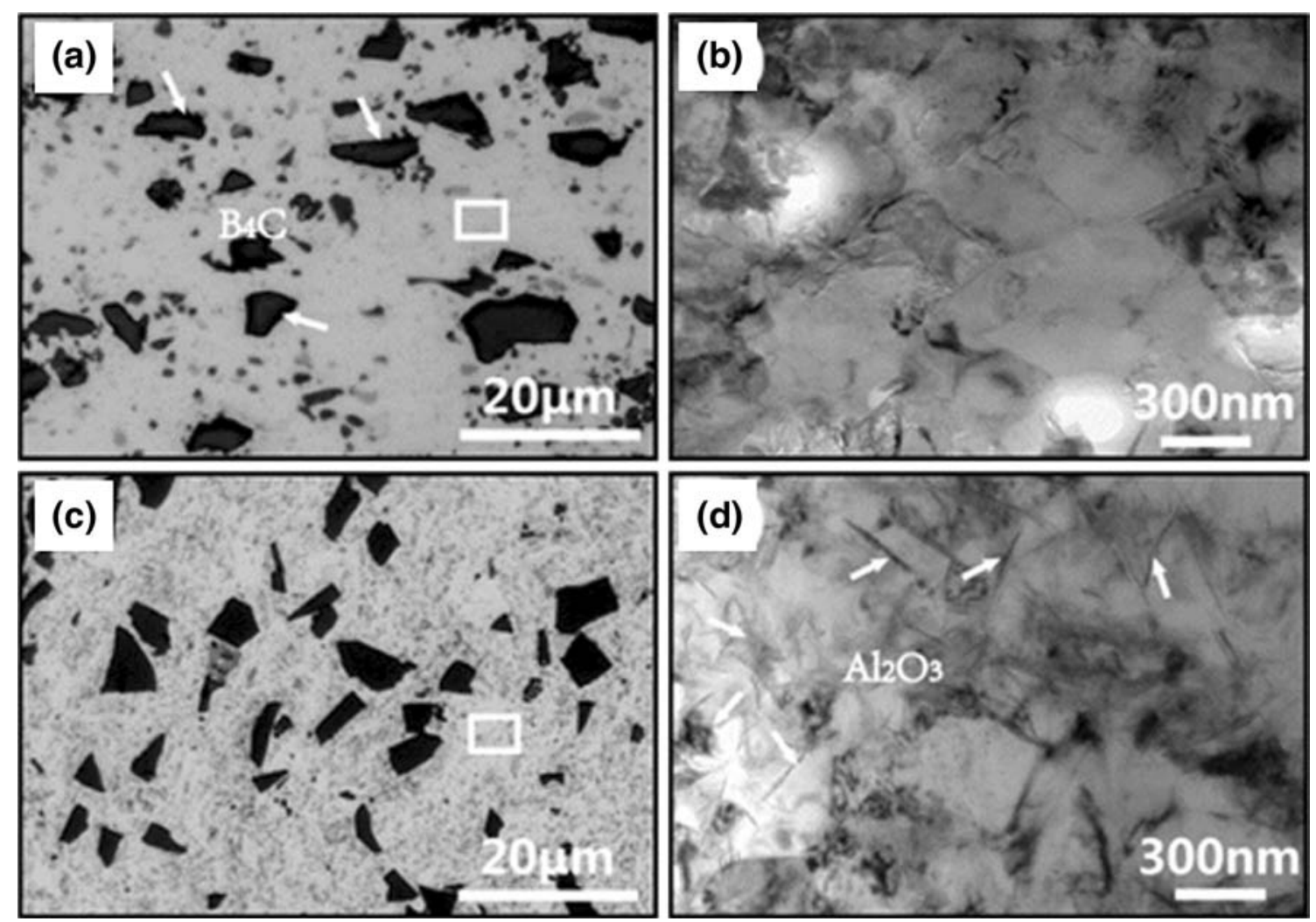

Fig. $6 \mathrm{OM}$ images of $\mathrm{B}_{4} \mathrm{C} / \mathrm{Al} \mathbf{a}, \mathrm{B}_{4} \mathrm{C} / \mathrm{Al}\left(\mathrm{Al}_{2} \mathrm{O}_{3}\right) \mathbf{c}$ composites, TEM images of the matrix of $\mathrm{B}_{4} \mathrm{C} / \mathrm{Al} \mathbf{b}, \mathrm{B}_{4} \mathrm{C} / \mathrm{Al}\left(\mathrm{Al}_{2} \mathrm{O}_{3}\right) \mathbf{d}$ composites
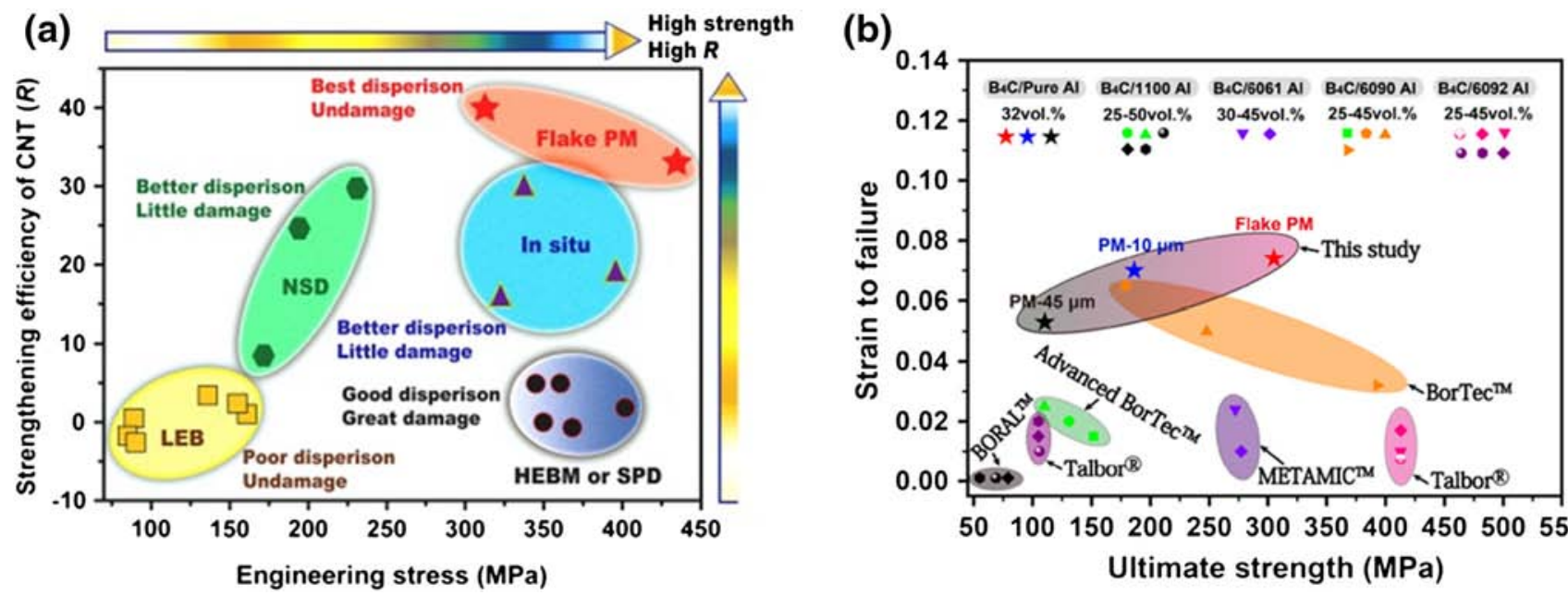

Fig. 7 a The strengthening efficiency and tensile strength for CNT/Al composites fabricated by various methods [19], b tensile properties of 32 vol. $\% \mathrm{~B}_{4} \mathrm{C} / \mathrm{Al}$ composites fabricated by flake $\mathrm{PM}$ and the commercial $\mathrm{B}_{4} \mathrm{C} / \mathrm{Al}$ composites, manufactured by leading composite companies [12]

using flake PM could produce various MMCs with different architectures and micro characteristics.

MMCs produced by flake PM exhibited notable improvements in mechanical properties compared with other methods. The flake PM produced laminated $\mathrm{Al}_{2} \mathrm{O}_{3} / \mathrm{Al}$ composites exhibiting excellent combinations of strength
(262 MPa) and ductility (22.9\%), which not only exceed the properties of composites produced by normal severe plastic deformation such as equal-channel angular pressing, but also was effective and convenient for massive production, compared with some special methods such as high-pressure torsion and friction stir processing, which 

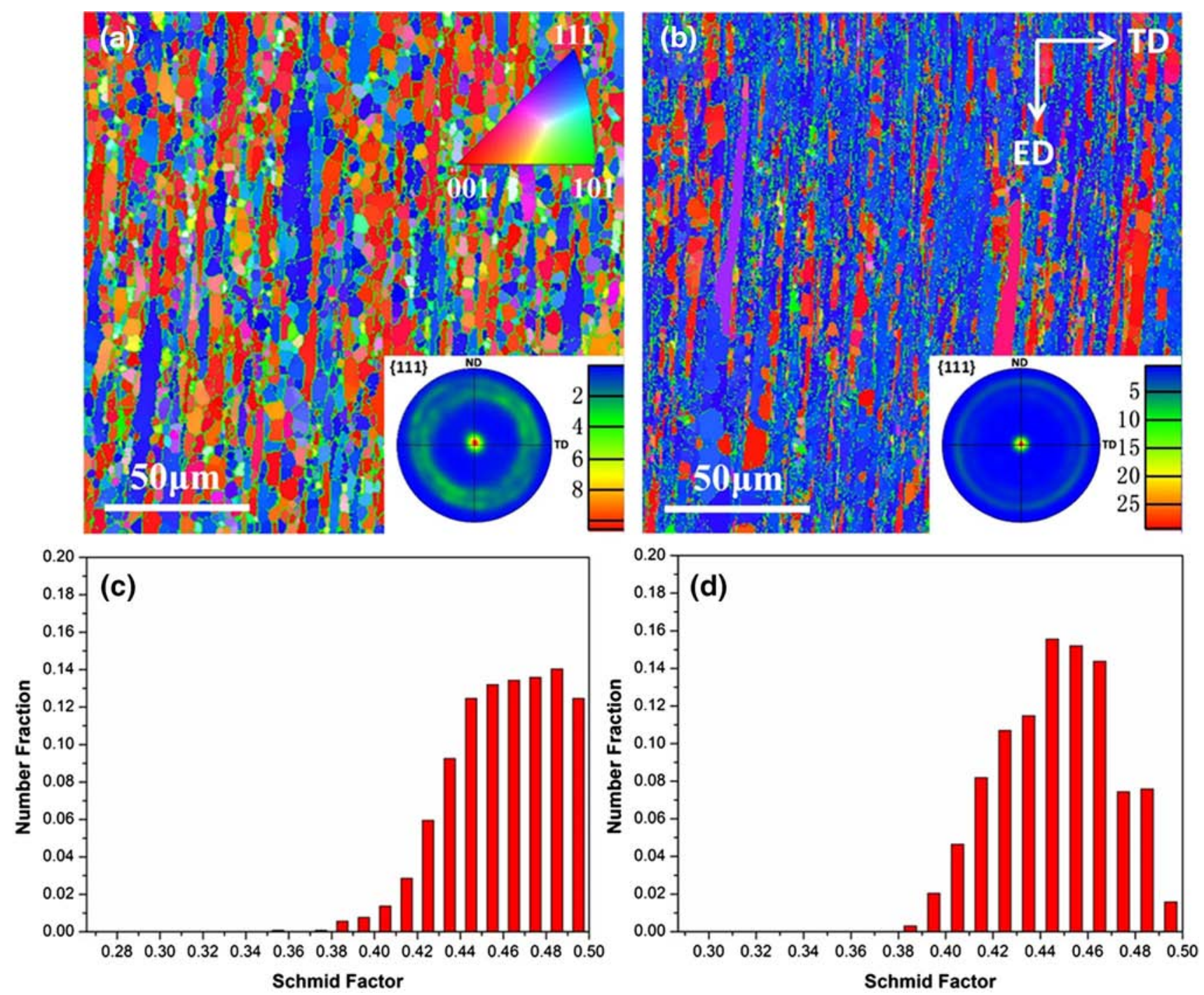

Fig. 8 EBSD maps of the disordered $\mathbf{a}$, laminated $\mathbf{b}$ composites, the inset in the bottom right-hand corner is the $\{111\}$ pole figure, ED, TD and ND represent the extrusion direction, transverse direction and normal direction, respectively. Schmid factors of a c, $\mathbf{b} \mathbf{d}$ in the ED

could also produce strong and ductile $\mathrm{Al}_{2} \mathrm{O}_{3} / \mathrm{Al}$ composites [9]. Also, remarkable improvements in both strength and ductility have also been observed in flake PM produced $\mathrm{CNT} / \mathrm{Al}, \mathrm{CNT} / 7075 \mathrm{Al}, \mathrm{B}_{4} \mathrm{C} / \mathrm{Al}$ composites, compared with those by conventional PM. In 1.0 vol.\% flake PM produced CNT/Al composites, about $13.6 \%$ increase in tensile strength and about $100 \%$ increase in total elongation as compared to conventional PM produced composites, were observed [16]. The flake PM produced CNT/7075 composites exhibited high modulus ( $88 \mathrm{GPa}$ ), excellent tensile strength $(820 \mathrm{MPa})$, and good total elongation (5\%), which were all improved compared with conventional PM [6]. The advantage of flake PM over other methods can be further seen by comparing the strengthening efficiency of CNTs $(R)$, which can be defined as:
$R=\frac{\sigma_{\mathrm{c}}-\sigma_{\mathrm{m}}}{V_{\mathrm{CNT}} \sigma_{\mathrm{m}}}$,

where $R$ is the value of strengthening efficiency, $\sigma_{\mathrm{c}}$ and $\sigma_{\mathrm{m}}$ is the tensile strength of the composite and the matrix, respectively, and $V_{\mathrm{CNT}}$ is the volume fraction of CNTs. Figure $7 \mathrm{a}$ compares the engineering stress and strengthening efficiency of CNTs/Al composites produced with different methods. It is evident that the strengthening efficiency of CNTs in flake PM composites are much higher than others, which indicates the capacity of flake PM in achieving excellent performance of the products.

Flake PM could also improve both strength and elongation of $32 \mathrm{vol} . \%$ (about $63.9 \%$ improvement in strength and $5.7 \%$ improvement in elongation as compared to conventional PM), and 16 vol.\% (about $15.2 \%$ improvement in 
strength and $85.4 \%$ improvement in elongation as comparing to conventional $\mathrm{PM}) \mathrm{B}_{4} \mathrm{C} / \mathrm{Al}$ composites $[12,13]$. Figure $7 \mathrm{~b}$ compares the ultimate strength and strain to failure of $\mathrm{B}_{4} \mathrm{C} / \mathrm{Al}$ composites produced by flake PM and manufactured by leading composite companies. The flake PM produced $\mathrm{B}_{4} \mathrm{C} / \mathrm{Al}$ composites exhibited excellent balance of strength and ductility. Furthermore, considering the matrix in previous flake PM produced composites was pure $\mathrm{Al}$, the strengthening efficiency of flake $\mathrm{PM}$ produced $\mathrm{B}_{4} \mathrm{C} / \mathrm{Al}$ composites was also excellent.

In a word, the use of flake PM could result in the biomimetic laminated structure, when the flake shape of the metal powders was maintained, or the structure of UFG with nano dispersoids, when the flake shape was destroyed. With these artfully designed micro architectures introduced by flake PM, significant improvements in the strength and ductility of MMCs have been achieved.

\section{Strengthening and Toughening Mechanism of MMCs Produced with Flake PM}

As shown in previous reports, obvious improvements in strength and ductility have been proved in MMCs produced by flake PM. The strengthening mechanisms were different in different materials, but have their generality derived from the flake powders.

Firstly, the uniform dispersion of reinforcements, which ensured the structure uniformity of the materials, prevented the property damages caused by the reinforcement agglomeration. This was the basic requirement for producing high performance MMCs.

When the flake shape of metal powders was maintained in the composites, enhancements of the strength and ductility of the materials was brought in by the alignment of reinforcements, the texture formed in the Al layers, and the laminated structure. As mentioned in Sect. 2.2, $\mathrm{Al}_{2} \mathrm{O}_{3}$ platelets and CNTs lied along the extrusion direction and the composites were laminated structured. The reinforcement alignment was important for the load bearing of the inequiaxial reinforcements, determining the modulus and tensile strength of the MMCs, which is the main reason of the high strengthening efficiency of CNTs in flake PM in Fig. 7a. Moreover, the strength enhancement of the flake PM materials was also attributed to the texture forming in the Al layers. The electron backscattered diffraction (EBSD) maps of the laminated (Fig. 8b) CNT/7055Al composites produced by flake PM indicated the introduction of the strong and single $\langle 111\rangle$ fiber texture, which was a hard orientation for tension in face-centered-cubic $\mathrm{Al}$ with classical $\{111\}-\langle 110\rangle-$ slip systems, compared with the disordered composites (Fig. 8a) produced by conventional PM [6]. A lower value of Schmid factor for the flake
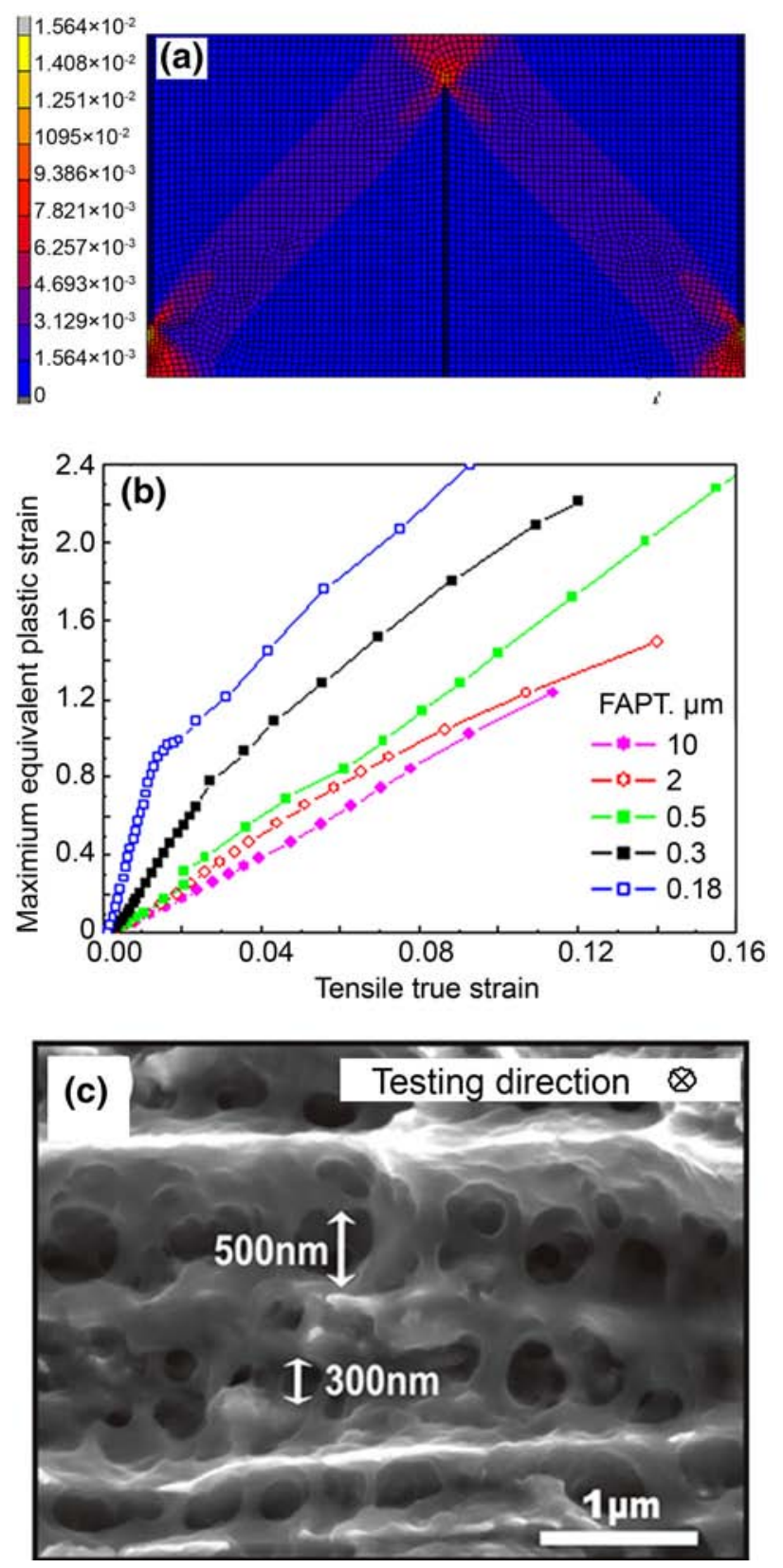

Fig. 9 a An equivalent plastic strain distribution at a tensile strain of 0.012 and a powder thickness of $500 \mathrm{~nm}$, b maximum equivalent plastic strain as a function of tensile strain, $\mathbf{c}$ fracture surfaces of $\mathrm{Al}_{2} \mathrm{O}_{3} / \mathrm{Al}$ nano laminated composites

PM produced laminated composites than for the disordered composites was calculated as shown in Fig. 8c, d, which is favorable to improve the yield strength (about $10 \%$ improvement from 698 to $771 \mathrm{MPa}$ ) according to the Schmid law.

A key reason for the increased ductility was that the nano laminated structure could enable the full potential of the reinforcements to hinder recovery and keep dislocations in the small grains. The dislocation density of flake 

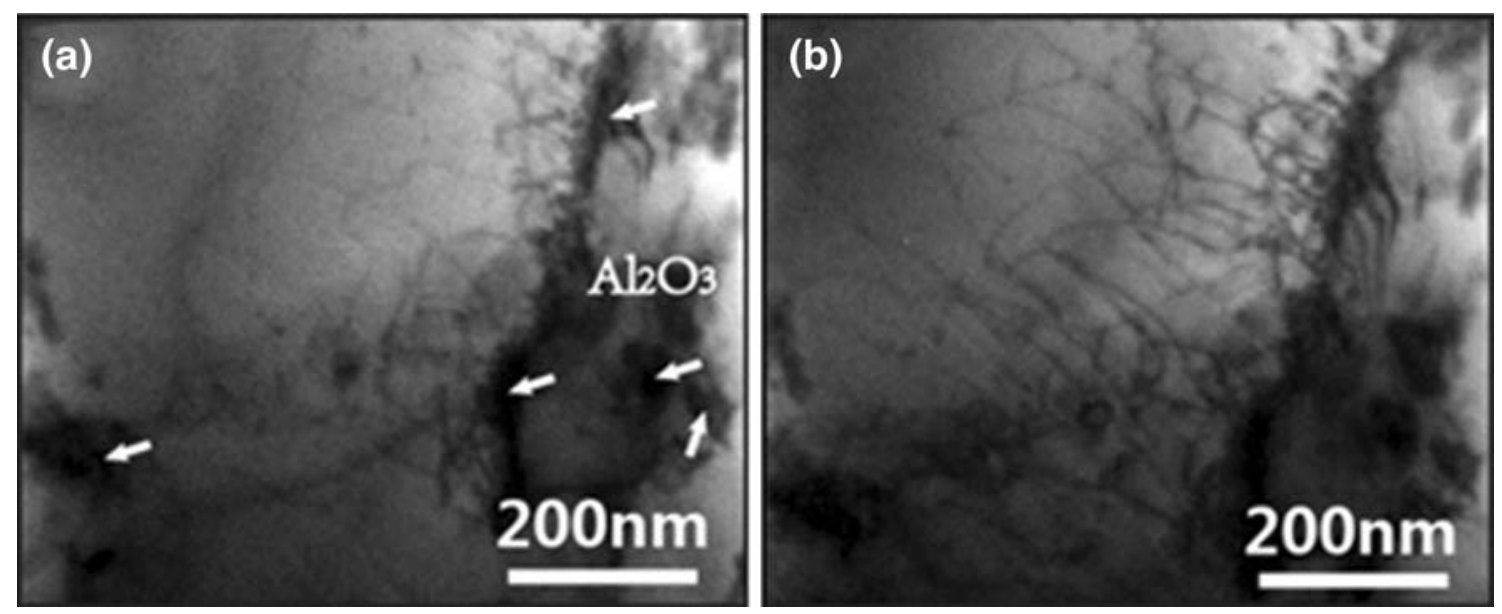

Fig. 10 TEM images of the $\mathrm{B}_{4} \mathrm{C} / \mathrm{Al}\left(\mathrm{Al}_{2} \mathrm{O}_{3}\right)$ during in situ tensile test before tensile test a, after tensile test at the strain of $\sim 0.005 \mathbf{b}$

PM produced CNTs/Al composite $\left(11.5 \times 10^{14} \mathrm{~m}^{-2}\right)$ is much higher than that of pure $\mathrm{Al}\left(1.33 \times 10^{14} \mathrm{~m}^{-2}\right)$ with similar grain size and about twice that of convention PM produced composite [16], indicating that the nanolaminate composites with 2-D aligned distribution of CNTs have a higher recovery-hindering efficiency than that of composites with 3-D random distribution of CNTs. Significant dislocation storage is required for compatible plastic strains of metal materials, allowing a high strain-hardening rate, which leads to larger uniform strains while maintaining a high level of strength [20,21]. Thus, the increased ductility was achieved in the flake PM CNT/Al nanocomposites. The toughening mechanism of the nanolaminated structure shall be studied in more details in future work.

Also, the thickness of the flake $\mathrm{Al}$ powders would influence the strength and ductility of the composites. The numerical models [22] indicated that, in laminated $\mathrm{Al}_{2} \mathrm{O}_{3} /$ $\mathrm{Al}$ composites, when the flake $\mathrm{Al}$ powder thickness was smaller than $500 \mathrm{~nm}$, the volume fraction of $\mathrm{Al}_{2} \mathrm{O}_{3}$ makes the main contribution to the strength of the composites, while when the flake $\mathrm{Al}$ powder thickness is larger than $500 \mathrm{~nm}$, the dominant contribution becomes the strength of the matrix. According to the finite-element analysis, the maximum equivalent plastic strain, at which cracks tend to appear, occurs in the matrix close to the ends of $\mathrm{Al}_{2} \mathrm{O}_{3}$ platelets (Fig. 8a), and increases with tensile strain and decreases with the flake $\mathrm{Al}$ powder thickness (Fig. 8b). Thus, a higher flake Al powder thickness would result in better ductility. The finite-element analysis also predicted that, the tensile strength increased monotonously with the decreasing flake $\mathrm{Al}$ powder thickness, while at a flake $\mathrm{Al}$ powder thickness of $500 \mathrm{~nm}$, a well-balanced strength and ductility was achieved, resulting in a maximum work of fracture, which also was proved with experimental results. The ductile failure of the $\mathrm{Al}_{2} \mathrm{O}_{3} / \mathrm{Al}$ nanolaminated composites can also be seen from the fracture surface shown in Fig. 9c [9]: the elongated dimples (indicating large plastic deformation) exhibited a size about $300-500 \mathrm{~nm}$, which is similar to the thickness of the laminated Al layers, indicating the good ductility of the composites.

When the flake shape of metal powders was destroyed in the composites, the UFG matrix and the dispersed nano reinforcements introduced by flake PM could enhance the strength and ductility of the composites. The fine-grain strengthening by UFG matrix, which could be described by Hall-Petch relationship, could improve the strength of the composites, but also leading to a lower strain hardening ability. Usually, the dislocations in UFG Al tend to escape to the grain boundaries through crossslip behavior and then annihilate in the form of dynamic recovery, which tremendously decreases the dislocation density inside the grains, leading to a lower strain hardening ability [23]. Dispersed nano reinforcements introduced by flake PM could act as obstacles for dislocation motion, and can trap mobile dislocations which increase the probability for subsequent dislocation-dislocation interactions, leading to more significant strain hardening ability. With dispersed nano reinforcements, the dislocation capacity of the materials could be increased significantly. Figure 10 shows TEM images taken during in situ tensile tests of $\mathrm{B}_{4} \mathrm{C} / \mathrm{Al}$ composites with $\mathrm{Al}_{2} \mathrm{O}_{3}$ nano dispersoids. It is clearly demonstrated that these additional dislocations induced by the mismatch of $\mathrm{Al}$ matrix and $\mathrm{Al}_{2} \mathrm{O}_{3}$ nano dispersoids inside the grains, were mostly pinned around the dispersoids (Fig. 10a).

In a word, with better reinforcement dispersion, orientated alignment of reinforcements, textures, laminated structures, UFG, and nano dipersoids, the MMCs produced 
with flake PM could be strong and ductile. Those strengthening and toughening mechanisms indicated that, with artfully designed composing and consolidation processes, the effective enhancement and promising future application of this new fabrication strategy could be possible.

\section{Conclusions and Outlook}

The developments of flake PM in fabricating MMCs have been reviewed. Flake PM is a strategy that uses flake metal powders to mix with the reinforcements and produce MMCs with designed structure. It has been proven that, by flake PM, uniform dispersion of nano $\mathrm{Al}_{2} \mathrm{O}_{3}$ flakes, nano $\mathrm{Al}_{2} \mathrm{O}_{3}$ particles, CNTs, GNSs, and micro $\mathrm{B}_{4} \mathrm{C}$ particles in $\mathrm{Al}$ or $\mathrm{Cu}$ matrix could be obtained. By artfully designed composing and consolidation processes, nanolaminated or hierarchical architectures and the enhancements of strength and ductility in MMCs were achieved. The enhancements of strength and ductility in flake PM produced MMCs were generally attributed to the improvement of reinforcement dispersion, reinforcement alignment, texture, the laminated structure, and nano dispersoids.

With a series of studies, flake PM was proved to be a useful and effective strategy in MMCs production. The strategy, which has only been developed for a few years, is still novel and needs to be intensively studied and further exploited in future. There remain lots of problems to be solved:

(1) The structure and texture evolution of the materials in the whole flake PM process, namely flaking process of metal powders, composing processes, powder consolidation processes, which could provide supports for the mechanism studies and property optimization of flake PM produced MMCs;

(2) The future mechanism studies of flake PM produced MMCs, which should take more factors into consideration, such as the texture of the materials, the reinforcement-matrix interface condition and so on; and further property optimization based on the mechanisms;

(3) The further application of flake PM in MMCs with wider component and architecture design.

In conclusion, great potential has been shown in flake PM for its wide applications in the future MMCs production, although great efforts are still needed to make the potential become reality. It is convincing that flake PM would provide effective thoughts for further development of MMCs for broader application in the future.

Acknowledgments This work was financially supported by the National Basic Research Program of China (No. 2012CB619600), the National Natural Science Foundation of China (Nos. 51131004, 51071100 and 51001071), the National High Technology Research and Development Program of China (No. 2012AA030311), and Shanghai Science and Technology Committee (No. 11JC1405500).

\section{References}

[1] D.B. Miracle, Compos. Sci. Technol. 65, 2526 (2005)

[2] K.K. Chawla, N. Chawla, Metal-Matrix Composites (Springer, New York, 2006), pp. 166-195

[3] D.L. Zhang, Prog. Mater. Sci. 49, 537 (2004)

[4] L. Jiang, G. Fan, Z. Li, X. Kai, D. Zhang, Z. Chen, S. Humphries, G. Heness, W.Y. Yeung, Carbon 49, 1965 (2011)

[5] Z. Li, L. Jiang, G. Fan, Y. Xu, D. Zhang, Z. Chen, S. Humphries, Micro Nano Lett. 5, 379 (2010)

[6] H. Wei, Z. Li, D.B. Xiong, Z. Tan, G. Fan, Z. Qin, D. Zhang, Scr. Mater. 75, 30 (2014)

[7] Z.Q. Tan, Z.Q. Li, G.L. Fan, W.H. Li, Q.L. Liu, Z. Wang, D. Zhang, Nanotechnology 22, 225603 (2011)

[8] J. Wang, Z. Li, G. Fan, H. Pan, Z. Chen, D. Zhang, Scr. Mater. 66, 594 (2012)

[9] L. Jiang, Z. Li, G. Fan, D. Zhang, Scr. Mater. 65, 412 (2011)

[10] L. Cao, Z. Li, G. Fan, L. Jiang, D. Zhang, W.J. Moon, Y.S. Kim, Carbon 50, 1057 (2012)

[11] J. Tang, G. Fan, Z. Li, X. Li, R. Xu, Y. Li, D. Zhang, W.J. Moon, S.D. Kaloshkin, M. Churyukanova, Carbon 55, 202 (2013)

[12] X.Z. Kai, Z.Q. Li, G.L. Fan, Q. Guo, D.B. Xiong, W.L. Zhang, Y.S. Su, W.J. Lu, W.J. Moon, D. Zhang, Mater. Sci. Eng. A 587, $46(2013)$

[13] X. Kai, Z. Li, G. Fan, Q. Guo, Z. Tan, W. Zhang, Y. Su, W. Lu, W.J. Moon, D. Zhang, Scr. Mater. 68, 555 (2013)

[14] X.Z. Kai, Z.Q. Li, W.L. Zhang, G.L. Fan, L. Jiang, W.J. Lu, D. Zhang, Mater. Sci. Eng. A 530, 574 (2011)

[15] L.J. Bonderer, A.R. Studart, L.J. Gauckler, Science 319, 1069 (2008)

[16] L. Jiang, Z. Li, G. Fan, L. Cao, D. Zhang, Scr. Mater. 66, 331 (2012)

[17] N. Guo, B. Luan, F. He, Z. Li, Q. Liu, Scr. Mater. 78, 1 (2014)

[18] G. Fan, X.Z. Kai, Z. Li, Q. Guo, Y. Su, D. Xiong, W.J. Moon, D. Zhang, in The 8th Pacific Rim International Congress on Advanced Materials and Processing (Wiley, Hoboken, 2013), pp. 1379-1385

[19] L. Jiang, Z. Li, G. Fan, L. Cao, D. Zhang, Carbon 50, 1993 (2012)

[20] H. Xiaoxu, N. Hansen, N. Tsuji, Science 312, 249 (2006)

[21] C.M. Hu, C.M. Lai, X.H. Du, N.J. Ho, J.C. Huang, Scr. Mater. 59, 1163 (2008)

[22] W. Zhang, Z. Li, L. Jiang, X. Kai, X. Dai, G. Fan, Q. Guo, D. Xiong, Y. Su, D. Zhang, Mater. Sci. Eng. A 594, 324 (2014)

[23] W. Vogel, Cryst. Res. Technol. 27, 882 (1992) 